\title{
Análise da Competitividade da Cadeia Vitivinícola do Rio Grande do Sul através do Ambiente Institucional
}

\section{Competitiveness Analysis from the Viti-winery Chain of Rio Grande do Sul Through the Institutional Environment}

Lauro Mattei ${ }^{1}$

Vinícius Triches ${ }^{2}$

Resumo: O trabalho faz uma descrição e análise dos principais cenários e desafios que caracterizam a competitividade da cadeia produtiva vitivinícola gaúcha, tomando-se como referência as potencialidades e restrições geradas pela configuração de seu ambiente institucional. Para tanto, utilizou-se como embasamento teórico a percepção de que a competitividade é um pressuposto de caráter sistêmico, além da relevância do papel desempenhado pelo ambiente institucional constituído. Dentre as principais constatações verificou-se que o ambiente institucional exerce grande influência nas atividades da cadeia. Além disso, verificou-se que o aumento da concorrência interna fez com que a vitivinicultura gaúcha se atualizasse tecnologicamente, buscando produzir de forma mais condizente com a nova realidade econômica do país decorrente do processo de abertura comercial dos anos de 1990. Assim, verificou-se que o ambiente institucional da cadeia é um fator que possibilita maior desenvolvimento, ao mesmo tempo em que opera como agente restritivo deste próprio desenvolvimento: ou seja, este ambiente exerce um duplo papel (positivo e negativo) no que se refere à competitividade.

Palavras-chave: Competitividade. Cadeia produtiva. Cadeia vitivinícola.

Abstract: The work ago a description $\mathcal{E}$ analysis from the principal scenes $\mathcal{E}$ defiances what they feature the competitiveness from chain productive viti-winery for the River Big of the South, taking reference the strength $\mathcal{E}$ restrictions generated by configuration of your environment institutional. About to as many, uses basement abstract the perception of what the competitiveness that's a presupposed of character systemic, beyond from relevance of the function acquit at environment

1 Doutor em Ciência Econômica pela Universidade Estadual de Campinas (UNICAMP). Professor Adjunto do Departamento de Ciências Econômicas da Universidade Federal de Santa Catarina (UFSC), Centro Sócio-Econômico, Bairro Trindade, Florianópolis/SC, CEP: 88040-970. E-Mail: mattei@cse.ufsc.br

2 Mestre em Economia pela Universidade Federal de Santa Catarina (UFSC). Professor Titular do Curso de Bacharelado em Administração de Empresas da Faculdade de Integração do Ensino Superior do Cone Sul (FISUL), Rua Presidente Vargas, 561, Bairro Centro, Telefone: (54) 3462-8300, Garibaldi/RS, CEP: 95720-000. E-Mail: vtriches@yahoo.com.br 
institutional constitution. In the midst of the chief verifies what the surroundings institutional exercise big influence on the activities from chain. Beyond that, verifies what the upswing from competition internal did with which the viti-viniculture of the River Big of the South if updates technological, picking produce of she forms more in keeping with the new reality economic of the country current of the sue of opening commercial from the years of 1990. Such, verifies what the surroundings institutional from chain that's a factor which enables major development, at the same moment what she operates I eat agent restrictive you gave proper development: in other words environment exercise a double function (positive and negative) as regards on the competitiveness.

Keywords: Competitiveness. Chain productive. Chain viti-winery.

JEL Classification: O18; R11.

\section{1 lntrodução}

A vitivinicultura (produção de uvas, vinhos e seus derivados) é uma atividade que remonta a milhares de anos, sendo sua prática historicamente vivenciada nas diferentes regiões do globo terrestre. O Brasil teve a introdução de videiras em seu território no século XVI. No Rio Grande do Sul (RS) a prática vitivinícola viria a se constituir, nas décadas finais do século XIX, em uma atividade de importância econômica para o estado. No decorrer das décadas iniciais do século XX a atividade continuou sua escala de desenvolvimento, com o início da implantação de uma legislação governamental e a chegada de enólogos estrangeiros que vieram auxiliar no aprimoramento técnico das agroindústrias, além de aumentos expressivos na produção e comercialização dos produtos da cadeia. Assim, lentas etapas de desenvolvimento determinaram o aumento progressivo da competitividade da atividade vitícola e da agroindústria nos períodos subsequentes.

O cenário atual da vitivinicultura gaúcha permite constatar que a atividade permanece como uma das mais importantes para a economia do estado rio-grandense, principalmente quando se observa o número de pessoas empregadas na cadeia, o valor dos impostos gerados, as exportações realizadas e as ações correlatas proporcionadas por esta atividade produtiva. Cabe destacar, por exemplo, em relação ao dinamismo correlato, as atividades de turismo, as quais "caminham e se organizam" conjuntamente com a vitivinicultura, principalmente na região da Serra Gaúcha, onde está localizado o principal pólo de desenvolvimento da cadeia no Rio Grande do Sul. Por isso, atualmente fala-se muito nas atividades de enoturismo. 
Ainda sobre a realidade atual da cadeia, é relevante destacar que, do ponto de vista das mudanças institucionais ocorridas no Brasil nas últimas décadas, muitas foram as dificuldades e desafios criados pela nova realidade econômica nacional, caracterizada pela abertura econômica, desregulamentação dos mercados, reformulação da política agrícola e estabilização econômica.

Dentre as principais consequências desse "novo modelo" pode-se destacar o aumento da concorrência com o produto de origem estrangeira (principalmente nos vinhos finos e espumantes), além da ampliação do leque de opções de investimentos na direção de produtos diferenciados ou segmentados na cadeia gaúcha e nacional. Assim, ocorreu uma formatação de novos padrões de plantio, produção e comercialização dos principais produtos da cadeia, levando a uma configuração nas últimas duas décadas de uma "revolução" no mapa produtivo e técnico das atividades vitivinícolas gaúcha e brasileira.

Diante desse cenário, o objetivo do presente artigo é ressaltar as características e os principais desafios enfrentados pela cadeia produtiva vitivinícola do estado do RS. Para tanto, utilizou-se da análise da competitividade de cadeias produtivas, buscando-se apresentar as potencialidades e gargalos apresentados especificamente no setor vitivinícola. $\mathrm{O}$ presente trabalho está dividido em quatro partes. Inicialmente, é destacada uma revisão teórica sobre o conceito e evolução da discussão sobre competitividade. Logo após, é apresentado um panorama da cadeia no $\mathrm{RS}$, com a apresentação de dados referentes a áreas plantadas, principais regiões da atividade no estado, produção e exportação de uva e vinho, além de seus principais derivados. A terceira parte do artigo versa sobre a análise da competitividade vitivinícola, observando nesse sentido os principais cenários e desafios da mesma, com foco nos limites impostos pelo seu ambiente institucional. Já a quarta e última parte apresenta as considerações finais.

\section{Breves Notas Sobre Competitividade}

A evolução da discussão sobre competitividade econômica pressupõe a superação das análises que consideram a mesma exclusivamente como um fator interno das empresas, ou seja, um fator eminentemente empresarial, situação em que o papel do mercado e das instituições é considerado como uma variável exógena e de importância irrelevante. Assume-se neste trabalho que o debate sobre a competitividade deve ser sistêmico, em que fatores extrafirma também são fundamentais para uma maior ou menor competitividade das empresas, cadeias produtivas, 
regiões e países. Nesse sentido, é feito a seguir uma breve síntese dos debates sobre a evolução da noção de competitividade.

\subsection{Abordagens Estáticas da Competitividade}

Embora esta abordagem seja relevante na economia mundial, é consenso entre diversos autores e pesquisadores a dificuldade para conceituar e aplicar metodologias que avaliem a competitividade como pressuposto fundamental do sucesso econômico. Assim, Kupfer (1991) destaca que a competitividade é um conceito virtualmente indefinido, devido aos diferentes enfoques e abrangências que fazem parte do mesmo.

Para Haguenauer (1989), os conceitos tradicionais referentes à competitividade podem ser agrupados em duas categorias: a competitividade vista como eficiência, sendo nesse sentido apresentada como dada (exante) e a competitividade como desempenho, apresentada como revelada (ex-post). Tais categorias constituem as chamadas vertentes tradicionais quando se analisam padrões de competitividade.

A competitividade vista como eficiência seria aquela relacionada à capacidade de uma firma ou indústria na produção de bens com maior eficácia que seus concorrentes, principalmente em relação aos preços, tecnologias e produtividade, entre outros fatores. Nesta categoria, o importante é a noção de que a competitividade é conseguida através da relação insumo-produto praticada pela firma, isso é, sua capacidade de converter os insumos em produtos com o máximo de rendimento possível.

De acordo com Ferraz et al. (1995):

É o produtor que, ao escolher as técnicas que utiliza, submetido às restrições impostas pela sua capacitação tecnológica, gerencial, financeira e comercial, estará definindo a sua competitividade. A competitividade é um fenômeno ex-ante, isto é, reflete o grau de capacitação detido pelas firmas, que se traduz nas técnicas por elas praticadas (FERRAZ et al., 1995, p. 2).

Já a competitividade vista como desempenho é expressa de acordo com a participação no mercado alcançada pela firma em um determinado momento. A participação das exportações da firma ou da indústria como um todo (conjunto de firmas) no comércio internacional da mercadoria seria o fator de indicação mais imediato dessa categoria de competitividade.

A competitividade construída ou revelada tem como fator primordial para seu sucesso a demanda do mercado, visto que o mesmo irá determinar quais produtos e de que empresas serão adquiridos, "aceitando" ou não as ações empresariais (produtivas, comerciais e de marketing) realizadas no período ex-ante. Assim: 
A competitividade é uma variável ex-post que sintetiza os fatores preço e não-preço - estes últimos incluem qualidade de produto e de fabricação e outros similares, a habilidade de servir ao mercado e a capacidade de diferenciação de produtos, fatores esses parcial ou totalmente subjetivos (FERRAZ et al., 1995, p. 2).

Entretanto, as noções de competitividade ex-post e ex-ante e seus respectivos pressupostos e consequências possuem deficiências que caracterizam as mesmas como ineficientes para a discussão sobre competitividade dentro de um enfoque dinâmico.

De acordo com Grassi (1997), a competitividade vista por essa metodologia carece de uma adequada análise de fenômenos baseados em vantagens competitivas construídas ao longo do tempo, visto que tais abordagens se apresentam como estáticas, permitindo apenas a apresentação do comportamento de indicadores até certo momento do tempo, ignorando as relações apresentadas pela evolução da competitividade.

Entre outros aspectos, o autor salienta o papel desempenhado pelas estratégias empresariais (ausente nas noções tradicionais citadas acima), apresentando duas observações que ajudam no entendimento da insuficiência mencionada. A primeira destaca que uma empresa pode ter bom desempenho no mercado sem ser eficiente; já a segunda leva em conta que uma empresa pode ser eficiente, mas não obter um desempenho ideal, visto que pode ter optado por uma estratégia equivocada, entre outros fatores. Finalmente, Grassi conclui que:

[...] para se garantir num nível sustentável de competitividade é importante que, além de eficiente, a empresa necessariamente tenha uma estratégia adequada, que permita traduzir esta eficiência em um bom desempenho no mercado - o que só se verifica ex-post (GRASSI, 1997, p. 9).

Kupfer (1991), na mesma linha que Grassi (1997), observa que os conceitos de eficiência e desempenho se caracterizam pela redução a mensuração, em pontos diversos da sequência temporal, dos resultados das diferentes estratégias competitivas empregadas pelas firmas, constituindo uma abordagem estática não adequada para a discussão sobre o processo competitivo. Nesse sentido, de acordo com o autor:

Tanto as características tecnológicas do processo de produção quanto as formas específicas de comercialização, se estão dadas em um momento do tempo para as firmas de um setor industrial, são o resultado de estratégias específicas adotadas em um momento anterior. Ainda no âmbito da firma, as decisões se dão no tempo, mas não expressam somente escolhas inter- 
temporais ótimas. Isto porque considera-se que o futuro é parcialmente desconhecido para as empresas e, portanto, as decisões são tomadas com base em expectativas incertas (KUPFER, 1991, p. 8-9).

Resumidamente, estas versões de competitividade, tanto a dada como a revelada, apresentariam argumentações e resultados restritos ao ambiente da firma, sendo, desSa forma, pouco eficientes para a análise do ambiente competitivo.

\subsection{Competitividade Sistêmica}

Um dos primeiros tratamentos para a percepção de uma competitividade de caráter sistêmico será destacado por Coutinho (1992). Segundo o autor, esse tipo de competitividade está relacionado a dois fatores principais. O primeiro deles, observado a partir dos anos de 1980 na economia mundial e, posteriormente, na economia brasileira, é o fato de que a competitividade atualmente:

Não se sustenta exclusivamente no dinamismo e na agilidade gerencial e inovacional da empresa privada, muito embora esta não tenha deixado de ser o veículo-chave de concretização da inovação tecnológica, isto é, da aplicação comercial, em escala econômica, de avanços científicos traduzidos em novos processos e produtos (COUTINHO, 1992, p. 79).

Outro fator relacionado às novas bases de competitividade citado pelo mesmo autor seria aquele que destaca que a competitividade em larga medida "[...] independe da dotação de fatores e de recursos naturais e tende a ser cada vez mais um resultado deliberado de estratégias privadas e/ou públicas de investimento com inovação" (COUTINHO, 1992, p. 80). Em outros termos, as vantagens comparativas, além de serem essencialmente dinâmicas, também seriam vantagens construídas e exercitadas ao longo do tempo, cuja manutenção requereria um esforço continuado.

Outro importante tratamento analítico para o estudo da competitividade sistêmica é realizado por Farina et al. (1997; 1999), considerando, assim como Coutinho, o novo ambiente competitivo da economia mundial, especialmente das últimas décadas. Esses também buscam uma análise sistêmica para a competitividade, o que requer novos níveis de agregação que ultrapassem o horizonte das firmas e o estabelecimento de outros elementos constitutivos na determinação de vantagens competitivas.

Essa percepção de competitividade de origem sistêmica é condizente com a dinâmica atual da economia mundial, que é caracterizada por mudanças que se manifestam de forma rápida, continuada e acelerada. A noção de competitividade, segundo essa abordagem permite uma 
visão abrangente das relações econômicas, bem como as formas em que os agentes econômicos serão afetados, além de verificar seus possíveis posicionamentos em resposta a esses movimentos.

Dessa forma, Farina et al. (1997; 1999), afirmam que a noção de cadeia produtiva deve ser vista como uma estrutura de análise frente ao dinâmico ambiente competitivo, que é caracterizado por inúmeras mudanças econômicas, tecnológicas e institucionais. Segundo Farina et al. (1996), citado em Cário et al. (2001):

Neste contexto, transformar as ameaças em oportunidades de negócios depende da existência de um sistema de coordenação capaz de transmitir informações, estímulos e controles ao longo de toda cadeia produtiva, a fim de viabilizar a nova estratégia. A adoção de pressupostos sistêmicos para a análise de um ambiente em reestruturação e de mudanças no seu padrão produtivo permitem o entendimento de sua estrutura de funcionamento e dos fatores de aporte ao seu desempenho competitivo, em que a interdependência e a inter-relação se verificam (FARINA et al. apud CÁRIO et al., 2001, p. 19-20).

Dentro desse esforço, é sugerido como método de descrição e análise da competitividade um conjunto de variáveis que englobe aspectos relativos ao ambiente institucional, tecnológico, organizacional, competitivo e as estratégias empresariais, entre outros. Com isso, percebe-se que a competitividade das empresas e, consequentemente, das cadeias produtivas, também será impactada pelas políticas públicas e privadas, dependendo tanto de ações de caráter individual como coletivas.

Esse fato, entretanto, sofre influência de um dos pressupostos básicos de qualquer sociedade organizada, ou seja, a instituição de regras que visem a restrição de determinados comportamentos por parte dos indivíduos. Dentro dessa lógica, é buscada a criação de estruturas que permitam a interação humana nos mais diversos níveis. Essas estruturas seriam as instituições, segundo destacou North (1994) em seu trabalho "Custos de Transação, Instituições e Desempenho Econômico".

Sabendo-se que as regras podem ser formais (destacadas por algum poder legítimo do país - ex: Constituição) ou informais (relacionadas ao conjunto de valores transmitidos pela sociedade - ex: costumes e códigos de conduta), o conceito de ambiente institucional está relacionado ao:

[...] conjunto de regras básicas sociais, legais e políticas que estabelecem as bases para a produção, a troca e a distribuição, tais como: as regras que definem os direitos de propriedade, os direitos de contrato etc. (WILLIAMSON apud FARINA et al., 1997, p. 27). 
Mudanças no ambiente institucional, ou seja, nas "regras do jogo", acabariam por provocar diversas reações e consequências nas decisões das organizações e dos indivíduos. Nesse sentido, processos de regulação e desregulamentação setorial e de fechamento ou abertura comercial representam o aparecimento de mudanças institucionais que aumentam ou diminuem a pressão competitiva e alteram as estratégias de crescimento e concorrência das empresas. Tais aspectos teriam impactos diretos na organização das cadeias produtivas.

North (1994) destaca duas alternativas que podem gerar um processo de mudança institucional. A primeira está relacionada a um maior entendimento dos agentes em relação às organizações existentes, tornando-as mais produtivas. Nesse caso, destacam-se os papéis desempenhados pelos processos de aprendizado e de habilidade. Já a outra alternativa está relacionada a um maior poder que pode surgir junto aos agentes econômicos, criando-se liberdade suficiente para a proposição de modificações nas regras e leis vigentes na sociedade.

Por fim, para North (1994), as instituições e sua evolução são fatores responsáveis pelo desempenho econômico e, quando aliadas à tecnologia, acabam por determinar os custos de produção e de transação, com influências decisivas sobre a competitividade.

\section{Panorama da Vitivinicultura no RS}

Histórica atividade econômica do povo gaúcho, com mais de um século de relevância econômica e social principalmente na Região da Serra Gaúcha, a vitivinicultura ainda hoje permanece como uma importante atividade econômica para o estado do RS. No que se refere aos valores monetários gerados pela cadeia gaúcha, estimativas do Instituto Brasileiro do Vinho (IBRAVIN) destacam que a cadeia apresenta um faturamento ao redor de 1,5 bilhões de reais por ano.

De acordo com estimativas de profissionais vinculados a entidades organizacionais, a cadeia vitivinícola gaúcha emprega ao redor de 100 mil pessoas. São trabalhadores vinculados à produção e comercialização de insumos, produtores de uva, vinicultores, além de segmentos que produzem vinhos e outros derivados, profissionais vinculados à distribuição dos produtos, entre outros.

A maior parte dos profissionais que trabalha na cadeia está ligada à produção de uva (viticultores), onde se estima que no estado existam atualmente entre 15 e 16 mil propriedades com plantio de vinhedos, distribuídos em cerca de 150 municípios. Esse número extremamente elevado é responsável, entre outros motivos, por colocar a uva como a principal cultura frutífera do estado, tanto em nível de hectares plantados como nos 
totais produzidos, de acordo com dados da Associação Rio-Grandense de Empreendimentos de Assistência Técnica do Estado do Rio Grande do Sul (EMATER/RS) (2008).

De acordo com dados do Instituto Brasileiro de Geografia e Estatística (IBGE) (2005), o RS possuía cerca de 42.450 hectares de área plantada de vinhedos, o que correspondia a 58\% do total de áreas do país. No que se refere à produção de uva, foram produzidos mais de 610 mil toneladas naquele ano, o que correspondeu a 49\% da totalidade nacional.

Já a agroindústria vitivinícola gaúcha envolve atualmente cerca de 700 estabelecimentos, incluídos tanto as vinícolas como as cooperativas, vinagrarias, cantinas familiares, entre outras. Quanto ao tamanho desses empreendimentos, destacam-se a grande maioria de micro e pequenas empresas, algumas médias e três empresas que podem ser consideradas como grandes, de acordo com classificação de Dolabella (2006).

A produção de vinhos gaúcha é responsável por cerca de $90 \%$ da totalidade brasileira, segundo estimativas das principais entidades organizacionais do estado e do Brasil. Assim, o RS produziu em 2005 cerca de 270 milhões de litros de vinhos (finos e comuns) segundo dados do Cadastro Vinícola do RS. Quanto aos outros derivados, dentre eles os espumantes, coolers, sangrias e outras bebidas, em 2005 foram pouco mais de 53 milhões de litros.

A preponderância gaúcha na produção de vinhos e outros derivados no âmbito do país é explicada, principalmente, pela presença das principais agroindústrias brasileiras no estado. Dentre elas destacam-se a Cooperativa Vinícola Aurora, Cooperativa Vinícola Garibaldi, Tecnovin, Vinícola Salton, Vinícola Miolo, dentre outras.

No que se refere à exportação, o RS é o estado-líder do país na venda de derivados para outros países. Destacam-se, nesse sentido, o suco de uva (8,6 milhões de litros exportados) e os vinhos (quase 2,8 milhões de litros), com ênfase nesse último para os finos, segundo dados da Secretaria de Comércio Exterior (SISTEMA ALICE, 2005). Já as vendas externas de espumantes foram praticamente irrelevantes no mesmo ano, quando atingiram apenas 79 mil litros.

Entretanto, quando se verifica a importação de produtos vitivinícolas, nota-se que o estado é um grande importador de vinhos (exclusivamente os finos, nesse caso), com compras externas de mais de 3,6 milhões de litros em 2005. Os elevados números gaúchos acompanham uma tendência brasileira, que importou em 2005 quase 38 milhões de litros da bebida. Entretanto, enquanto as importações gaúchas se mantêm com valores razoavelmente estáveis desde o ano 2000, as importações brasileiras tiveram um acréscimo de mais de $28 \%$ no período $2000-2005$. Quanto 
às importações de espumantes pelo estado do RS, essas também foram relevantes, com cerca de 960 mil litros em 2005, de acordo com a mesma fonte.

Por fim, quando se observa a importância da vitivinicultura para as diversas regiões produtoras gaúchas, importantes peculiaridades são apresentadas. Na Região Nordeste do RS (incluindo-se as três maiores regiões em quantidade de hectares, ou seja, Caxias do Sul, Guaporé e Vacaria) a produção de uva é baseada em pequenas propriedades rurais, com média de 15 hectares por área total e disponibilidade média de quatro pessoas por propriedade para trabalhar no cultivo das uvas.

Na microrregião de Caxias do Sul, área líder na produção de uva, vinho e seus derivados no estado, o município com maior número de propriedades com plantio de vinhedos é Bento Gonçalves. De acordo com dados do Cadastro Vitícola de 2004, o município possuía 1.781 propriedades com plantio de vinhedos. Logo a seguir aparece Caxias do Sul (1.742 propriedades), Flores da Cunha (1.452), Farroupilha (1.452), Farroupilha (1.337), Garibaldi (1.175), Antônio Prado (698) e Monte Belo do Sul (594).

Devido à topografia acidentada dessas regiões, o emprego da mecanização nos parreirais é dificultado, contribuindo assim para o uso de mãode-obra familiar, fato que remonta ao período de chegada dos imigrantes italianos a essas regiões. A possibilidade de fixação do homem no meio rural, proporcionada este modalidade de vitivinicultura, cuja dinâmica é dada pelas pequenas propriedades e pelo uso intensivo de mão-de-obra familiar, acabou contribuindo para a conformação de um elevado padrão de desenvolvimento social (melhor distribuição de renda) nessas regiões, comparativamente a outras regiões gaúchas.

Nas áreas mais recentes de plantio de uva no RS, a produção destacase por utilização de pouca mão-de-obra (com exceção das regiões de Uruguaiana e Quarai), visto que a exploração empresarial nesses casos é caracterizada pelo uso de grandes áreas de parreirais de variedades viníferas, o que acaba por requerer processos intensivos de mecanização. Nesse caso, destacam-se as regiões da Serra do Sudeste, Campanha Meridional e Campanha Central.

Mesmo que se utilize pouca mão-de-obra, a vitivinicultura nessas regiões (inserida dentro da chamada "Metade Sul" do RS) é um fator de dinamização das economias locais, visto se tratar de regiões com os piores índices de desenvolvimento econômico do estado, com uma indústria pouco dinâmica e um setor agropecuário pouco diversificado. Assim, a atividade acaba sendo uma das alternativas para a retomada do crescimento e desenvolvimento econômico das referidas regiões.

Outro aspecto fundamental que realça a importância da vitivinicultura para as regiões gaúchas, especialmente no caso da Serra Gaúcha, é 
o dinamismo correlato proporcionado pelas atividades da cadeia, principalmente àquelas referentes ao enoturismo. De acordo com a Associação dos Produtores de Vinhos Finos do Vale dos Vinhedos (APROVALE), o enoturismo é "um segmento da atividade turística que se fundamenta na viagem motivada pela apreciação do sabor e aroma dos vinhos e das tradições e tipicidade das localidades que produzem esta bebida" (APROVALE, 2007). Vinculado em grande parte ao gastroturismo baseado na origem italiana, o enoturismo é uma atividade de grande crescimento no estado nos últimos anos, especialmente na região de Caxias do Sul.

Entre as novidades que se desenvolveram em maior escala nos últimos anos destacam-se a ampliação de serviços que visam a recepção adequada de turistas dos mais diferentes lugares, como a criação de roteiros de vinícolas dos municípios, onde é possível conhecer as instalações das mesmas, além de ter também acesso a varejos, restaurantes, museus e outros estabelecimentos que colaboram para a permanência dos mesmos.

Para se ter uma ideia da importância que é dada ao enoturismo na região da Serra, nota-se que essa conta com os Caminhos de Pedra (roteiro que inclui vinícolas, restaurantes, arquitetura italiana e estabelecimentos diversos no interior de Bento Gonçalves e de Caxias do Sul); o Vale dos Vinhedos (visitação a mais de 20 vinícolas e ao Memorial do Vinho, além da realização de trilhas e visita a capelas); Vinhos de Montanha (visitação a vinícolas e gastronomia no distrito de Pinto Bandeira, pertencente a Bento Gonçalves); Caminhos de Faria Lemos (visita a viticultores de uvas finas e pequenas cantinas no Vale Aurora, região de Bento Gonçalves); e o Roteiro dos Vinhos dos Altos Montes (visitação a vinícolas e restaurantes dos municípios de Flores da Cunha e Nova Pádua) entre as principais iniciativas que visam o incentivo das atividades turísticas associadas às atividades vinículas propriamente ditas.

Nesse caso, destaca-se um investimento de grande porte que acelerou o desenvolvimento do enoturismo na região. Trata-se de um complexo que envolve hotel e um spa do vinho, além de uma vinícola própria e um centro de convenções, tudo em um mesmo empreendimento, cuja inauguração ocorreu no ano de 2007 no Vale dos Vinhedos.

A viabilização das atividades do enoturismo acaba sendo importante devido a dois aspectos fundamentais: torna-se mais uma alternativa de renda para viticultores e vinicultores tradicionais das regiões e colabora para dinamização das regiões produtoras de vinho demarcadas, ou seja, aquelas onde existem associações de produtores que visam obter indicação de procedência (e posteriormente denominação de origem) para seus produtos. 


\section{Análise da Competitividade da Cadeia Vitivinícola do RS através do Ambiente Institucional}

De fundamental importância para o desenvolvimento ou não de uma cadeia produtiva, as principais características que compõem o ambiente institucional da cadeia vitivinícola gaúcha foram divididas em dois tópicos, visando uma melhor compreensão do tema. O primeiro deles trata da importância das políticas governamentais e o segundo discute os efeitos da legislação no desenvolvimento das atividades da cadeia vitivinícola.

\subsection{Políticas Governamentais}

Considerando-se que toda política de origem governamental tem importância fundamental no aumento ou redução da competitividade de uma cadeia produtiva, a seguir será destacada a atuação governamental em algumas áreas específicas, procurando realçar a maneira como as políticas governamentais afetam a vitivinicultura gaúcha.

\subsubsection{Política de Comércio Exterior}

A política de comércio exterior do governo federal, ou seja, a inserção externa brasileira na economia mundial, afetou e continua afetando a competitividade da cadeia produtiva vitivinícola gaúcha. A abertura comercial iniciada nos anos 1990 e a efetivação do Mercosul, aliada a outros fatores, foram responsáveis pela ampliação dos níveis de importações de produtos vitivinícolas, com destaque para os vinhos e espumantes, sendo considerado nesse sentido um aspecto negativo para o aumento da competitividade, tendo em vista a perda de mercado gerada à vitivinicultura gaúcha.

Entretanto, alguns aspectos positivos também podem ser encontrados na inserção externa nacional, fazendo com que a vitivinicultura nacional e gaúcha fosse obrigada a se adaptar à nova realidade econômica do país, sobretudo crescendo de forma qualitativa. É desse modo que são destacados melhorias nos processos tecnológicos de produção vitícola e na vinificação; maior ênfase nas estratégias empresariais; ampliação de políticas de marketing e promoção de produtos, além do começo de uma sintonia maior entre viticultores e agroindústria.

Dentro dessa lógica, considera-se que a inserção externa brasileira, com suas consequências para a cadeia de uvas, vinhos e outros derivados do RS, tem seus aspectos negativos e positivos. Assim, nota-se que se por um lado houve um maior acirramento comercial, via perda de mercados interno e externo, com consequências diversas para os variados segmentos da cadeia, por outro gestou-se uma nova configuração empresarial, 
organizacional e de governança, mais adequada aos novos tempos, que tenta de alguma forma superar os enormes desafios lançados, visando ampliar oportunidades percebidas.

Mas há um outro aspecto negativo para a competitividade da cadeia gaúcha relacionado aos acordos bilaterais realizados pelo governo brasileiro com o Chile e outros países. Na relação com os chilenos, em troca de favorecimentos para uma maior exportação de produtos do complexo metal-mecânico nacional, a vitivinicultura gaúcha tem sido usada como "moeda de troca" pelo governo federal, o que dá garantia para que o vinho fino daquele país avance sobre o mercado nacional.

\subsubsection{Política Tributária}

A elevada carga de tributos no Brasil é um fator que prejudica praticamente todas as atividades econômicas, não sendo diferente com a vitivinicultura gaúcha. Além disso, a desorganização tributária (cobrança de impostos em cascata, diferenças de alíquotas de impostos entre os estados, entre outras) acaba por prejudicar ainda mais o desenvolvimento das atividades da cadeia gaúcha em questão. É nesse sentido que a atividade é afetada negativamente por esse instrumento de política pública, sendo considerado por muitos atores sociais envolvidos com a cadeia como o principal gargalo que afeta a competitividade da mesma, sendo considerado mais importante do que as consequências advindas da inserção externa da economia brasileira.

Em informação verbal destacada por um representante do IBRAVIN durante uma palestra no $1^{\circ}$ Workshop Fenavinho Brasil (Bento Gonçalves/ RS, fevereiro de 2007), diversas são as distorções tributárias que afetam a cadeia, ainda mais visíveis quando se compara a estrutura tributária e os custos de produção das atividades vitivinícolas brasileiras com aquelas de outros países concorrentes, principalmente Chile e Argentina. Através de uma comparação com outros países, busca-se aqui apresentar uma confirmação técnica de como uma carga tributária elevada pode ser um fator de perda de competitividade para um país como o Brasil e, particularmente, para a vitivinicultura do RS.

Entre o número de obrigações tributárias que afetam as atividades vitivinícolas nos países, o Chile se destaca por um sistema tributário que contém apenas três impostos, enquanto no Brasil, ao longo das três esferas, são mais de vinte tipos diferentes, subdivididos em impostos, taxas, contribuições sociais, entre outras modalidades.

A menor tributação incidente sobre as atividades vitivinícolas no Chile em comparação ao Brasil é devida, em grande parte, ao país possuir uma tributação simplificada, visto que o vinho chileno em seu mercado interno sofre apenas a incidência do imposto sobre valor agregado (IVA) 
- com alíquota de 19\% -, um imposto adicional às bebidas - com alíquota de $15 \%$ - e o imposto de renda. Quando o vinho chileno é exportado, o IVA gera créditos tributários, além de também receber uma isenção do imposto adicional às bebidas. Já na Argentina ocorreu a assinatura do Convênio da Competitividade entre governo federal, governos das províncias e representantes vitivinícolas, que resultou em diversas isenções de impostos que diminuíram a carga tributária sobre o vinho argentino ainda nos primeiros anos deste século.

Outro aspecto interessante que deve ser considerado também é o encarecimento ainda maior dos produtos nacionais gerado por tributos como o PIS e COFINS, que representam em torno de 9 a $10 \%$ do valor final do vinho (BRUCH, 2004). Para essa autora, Chile e Argentina não possuem tributos semelhantes a esses, visto que:

No Chile não há nenhuma contribuição social, posto que a seguridade social é financiada de forma privada. Na Argentina a contribuição social se limita a contribuições sobre a folha de pagamento. Mesmo neste caso, a tributação brasileira é maior: enquanto o empregador paga a alíquota de $20 \%$ sobre a folha de pagamento no Brasil, esta porcentagem cai para 16\% na Argentina (BRUCH, 2004, p. 85).

No que se refere à importação de insumos para atender as agroindústrias, uma vantagem competitiva dos vinicultores chilenos e argentinos é que os mesmos recebem isenção de impostos para alguns insumos que compõem o "custo seco", contrariamente aos segmentos da cadeia brasileira, que pagam impostos de importação nos insumos não-produzidos no país. De acordo com Schumacher (2006), no Brasil paga-se cerca de $10 \%$ de imposto de importação de rolhas de cortiça não fabricadas no país (insumo de importância fundamental para as vinícolas).

Todavia, a discussão acerca da isenção de impostos de importação pode ter outro fator complicante, uma vez que isentando-se as empresas que importam livremente, não se tem a garantia de que haverá condições para o aparecimento de empresas de origem nacional que poderiam vir a ocupar esse espaço de forma competitiva. Dessa forma, tal isenção é boa apenas para os vinicultores, mas é um fator negativo quando se imagina um desenvolvimento da competitividade de forma integrada na cadeia, favorecendo os diversos segmentos que fazem parte da mesma e não apenas um deles.

Ainda do ponto de vista da carga tributária nacional, nota-se que muitas vezes essa carga acaba sendo distinta para produtos similares. Isso decorre, principalmente, por causa dos diferentes estados de destino do produto, tipo de produto, valor agregado a esse e a taxa de lucro da empresa. Referente às alíquotas do Imposto de Circulação de Mercadorias e 
Serviços (ICMS), deve-se aqui considerar que o país possui 27 alíquotas diferentes.

Outra consequência do modelo de tributação existente na cadeia vitivinícola é que ele gera a falta de estímulos para engarrafar os vinhos em seu local de origem, sendo a bebida vendida a granel para outros estados, não gerando agregação de valor ao produto. De acordo com informações fornecidas pela Associação Gaúcha de Vinicultores (AGAVI), no RS paga-se sete centavos de real de ICMS por cada litro de vinho comum vendido a granel, enquanto o engarrafado pagaria um valor cerca de quatro vezes maior. Cabe aqui lembrar que, infelizmente, não é somente a vitivinicultura gaúcha que é afetada por esse tipo de distorção, mas diversas outras atividades econômicas no país.

Segundo o IBRAVIN (2008), essa distorção tributária é um dos fatores que acabou determinando que, em 2005, cerca de dois terços dos vinhos comuns comercializados pelo RS fossem vendidos a granel, principalmente para grandes engarrafadoras do estado de São Paulo, onde estão situadas estruturas de produção e distribuição tradicionalmente consolidadas. Assim, a venda de vinhos a granel acabou se tornando um importante meio de venda de vinhos pelas empresas gaúchas, sendo que algumas vinícolas se especializaram nessa modalidade de venda, enquanto outras destinam apenas uma parcela de sua produção para esse fim, como é o caso da Vinícola Aurora.

Estão em curso diversas tentativas de redução dos níveis de tributação. No país, de acordo com informações do presidente executivo do IBRAVIN, destacam-se a redução do valor do Imposto sobre Produtos Industrializados (IPI) para os espumantes de $30 \%$ para $20 \%$, por decreto, e de $20 \%$ para $10 \%$ por um ato normativo, além do enquadramento do produto na categoria dos vinhos e a conquista do crédito presumido de ICMS no RS de 5\% para o produto vendido internamente. Especificamente no RS, houve a tentativa, no ano de 2006, de redução da carga tributária através de projeto que enquadrava o vinho como alimento. No entanto, tal proposição não obteve êxito, especialmente devido à reação da opinião pública.

\subsubsection{Políticas de Financiamento}

A grande maioria dos viticultores gaúchos se encaixa nas condições do Programa Nacional de Fortalecimento da Agricultura Familiar (PRO$\mathrm{NAF}$ ), com grande destaque para os produtores da principal região produtora (Serra Gaúcha), onde predominam as pequenas propriedades agrícolas eminentemente familiares. Assim, a grande maioria dos viticultores acaba utilizando esse programa para as atividades de custeio e de investimento em suas propriedades. 
Entre as vantagens que levam a maioria desses viticultores a optarem pelas linhas do PRONAF estão os juros menores ( 3 a $4 \%$ ao ano), comparativamente às outras possibilidades de financiamento, como o Programa de Desenvolvimento da Fruticultura (PRODEFRUTA) do BNDES, com juros anuais maiores que o dobro dos juros praticados pelo PRONAF.

Com menor importância que os programas do Governo Federal (PRONAF e PRODEFRUTA), nota-se que também o governo do estado do RS tem um programa destinado a criar alternativas econômicas e sociais para os agricultores, principalmente os que praticam agricultura familiar. Mesmo com recursos limitados, esse apoio teve papel considerável desde a sua criação em 2003. Trata-se do Programa Estadual de Fruticultura (PROFRUTA/RS), que está sendo executado pela EMATER/RS, tendo como foco a implantação de novos pomares, projetos de custeio e de manutenção de pomares já existentes, assistência técnica e capacitação aos fruticultores, além do desenvolvimento de mudas frutíferas.

Para a compra de maquinário e outros investimentos por parte das vinícolas, destaca-se a possibilidade de obtenção de financiamentos através do Banco Nacional de Desenvolvimento Econômico e Social (BNDES), Banco do Brasil (BB) e Banco do Estado do Rio Grande do Sul (BANRISUL), nas seguintes modalidades de crédito:

- Programa de Incentivo à Irrigação e à Armazenagem (MODERINFRA): possibilidade de financiamento de pequenas cantinas rurais que possuem seus vinhedos e a cantina na mesma propriedade. Entretanto, é pouco utilizado porque os juros cobrados são considerados elevados (8,75\% ao ano);

- Linha Especial de Financiamento Agrícola (FINAME-ESPECIAL): utilizado em sua maior parte como possibilidade de financiamento para as cooperativas. Porém, as taxas de juros são consideradas elevadas (12,35\% ao ano), o que dificulta sua maior utilização por parte das agroindústrias.

Uma peculiaridade interessante no financiamento da atividade vitícola é que a mesma é amparada por uma política de garantia de preços mínimos (PGPM), instituída através do Decreto-Lei n 79, de 1966. Este decreto atribuiu à União o estabelecimento de normas para a fixação dos preços mínimos e a execução das operações de financiamento e aquisição de produtos agropecuários, tendo como órgão gestor a Companhia Nacional de Abastecimento (CONAB), vinculada ao Ministério da Agricultura, Pecuária e Abastecimento (MAPA). Além da fixação dos preços mínimos (estabelecido em 46 centavos ao quilo da uva para a safra 2007), destacaram-se historicamente como instrumentos da PGPM os Empréstimos do Governo Federal (EGF) e as Aquisições do Governo Federal (AGF). 
O EGF é utilizado para a compra da matéria-prima pelas vinícolas, tendo como base o preço mínimo da uva no ano. Quanto aos recursos do empréstimo, esses são fornecidos pelo MAPA e administrados pelo BB. Assim, como considerado nos financiamentos anteriores, uma das principais críticas ao EGF é que suas taxas de juros ainda são elevadas (entre 8 a $12 \%$ ao ano).

Segundo alguns segmentos da cadeia, a política de compra de estoques vinícolas por parte do Governo Federal (AGF) teria resultado em uma desestabilização do mercado de vinhos nacional, devido à venda posterior da bebida com preços muito baixos. Além disso, Lapolli et al. (1995) destacam mais dois fatores que colaboraram para o abandono do AGF: a restrição de recursos orçamentários e as prioridades institucionais voltadas ao abastecimento de produtos essenciais de alimentação.

Entre as alternativas à substituição do AGF, destacou-se a realização, no final de 2006, do primeiro Programa de Escoamento da Produção (PEP). O leilão do Governo Federal era restrito à venda de vinhos finos, mas com espaço para comercialização de 10\% de vinhos comuns. Quanto aos resultados, o leilão gerou uma comercialização de mais de 5,5 milhões de litros de vinho, que foram vendidos a um preço médio de vinho comum, com adição de mais $\mathrm{R} \$ 0,65$ por litro.

\subsubsection{Política de Fiscalização}

A política de fiscalização dos produtos nacionais e importados, operada através do convênio entre o MAPA e a Secretaria de Agricultura e Abastecimento do Estado do Rio Grande do Sul (SAA/RS), é um dos pontos com interpretações controversas entre os segmentos, uma vez que parte deles, especialmente aqueles com atuação empresarial ou membros de organizações de classe, realçou que a fiscalização é praticamente inoperante e/ou inexistente no país. Já existem outros segmentos que reconhecem as deficiências, mas afirmam que a fiscalização tem aumentado.

As críticas mais veementes de membros de organizações da cadeia e empresários se basearam na percepção de que a fiscalização do MAPA e da SAA/RS é deficitária, tanto no que se refere à verificação da qualidade dos produtos nacionais como em relação à qualidade dos produtos importados que entram no país. Além disso, quando a fiscalização do MAPA é feita, a reclamação é que ocorre apenas no RS, sem dar atenção aos outros estados brasileiros.

No tocante aos produtos nacionais, a crítica principal concentra-se sobre as novas bebidas que tiveram autorização para serem produzidas no país nos últimos anos, principalmente as sangrias e os coquetéis. Dentro dessa perspectiva, destaca-se que uma parte dessas bebidas, pelo fato de não serem fiscalizadas pelos órgãos públicos responsáveis, chega ao mer- 
cado não preenchendo os requisitos mínimos de qualidade delimitados pela legislação. Além disso, considera-se que essas bebidas muitas vezes acabam sendo vendidas como vinho, o que na verdade não são, visto que não são produzidas com $100 \%$ de composição de vinho.

Quanto à fiscalização dos produtos vitivinícolas importados que entram no país (principalmente vinhos e espumantes), os segmentos mais críticos à atuação dos órgãos governamentais destacam a entrada de produtos sem registro, não recebendo nenhum tipo de laudo por parte do MAPA. Essa informação é contestada por parte dos funcionários dos órgãos públicos, que afirmam que é muito mais fácil de serem encontradas irregularidades nos produtos nacionais do que nos importados, além de que praticamente nenhum produto entra no país de forma legal sem ser registrado e receber laudo atestando suas condições adequadas.

É visível que as dificuldades de fiscalização estão relacionadas, principalmente, à falta de recursos humanos e financeiros por parte da SAA/RS e do MAPA. Mesmo assim, equipes técnicas da SAA/RS e do MAPA destacam diversos avanços nos processos metodológicos para o reconhecimento de adulterações nos produtos nos últimos anos, o que começou a facilitar o trabalho desses órgãos. Dentre as novas metodologias empregadas, destacam-se:

- Metodologia do isótopo de carbono, que determina a origem do álcool encontrado no vinho. Posteriormente, descobriu-se que havia um meio de se burlar esse tipo de teste, o que contribuiu para que o mesmo fosse abandonado;

- Metodologia do oxigênio, que identifica a água exógena existente no vinho. Esse teste ainda é considerado um dos mais seguros contra formas de burlar os resultados.

Outro aspecto relativo à fiscalizações diz respeito ao comportamento dúbio (ambíguo) do setor produtivo: quando o MAPA e a SAA/RS realizam poucas fiscalizações são criticados e cobrados; já quando fazem mais do que o normal também são alvo de manifestações contrárias.

Quanto à evolução nas fiscalizações realizadas no Laboratório de Referência Enológica (LAREN), único laboratório autorizado no Estado, seu coordenador e também chefe da divisão de Enologia da SAA/RS destacou que o número de amostras coletadas e analisadas tem aumentado ano a ano, além da prestação de serviços às vinícolas, demonstrando o início de um processo de enquadramento do segmento produtivo da cadeia, através de percepção de que é preciso trabalhar com qualidade e honestidade.

Em linhas gerais, se percebe que houve melhorias na fiscalização da qualidade dos produtos nacionais e também dos importados nos últimos anos, apesar de todas as dificuldades enfrentadas pelos órgãos responsá- 
veis pela realização desse trabalho. Certamente a política de fiscalização do comércio legal ainda está longe do que realmente seria necessário, mas deve-se reconhecer que houve uma evolução significativa, principalmente após a criação e atuação do LAREN, órgão responsável pelo fechamento dos laboratórios antigos que operavam sem as condições necessárias.

\subsection{Efeitos da Legislação Sobre a Cadeia Produtiva}

A legislação que regulamenta a elaboração de produtos vitivinícolas no país e no RS pode ser considerada como coerente e atualizada de acordo com os princípios existentes nos principais países e mercados de uva e vinho do mundo. Mesmo assim, apresenta algumas lacunas e imperfeições, de acordo com a opinião de diversos segmentos da cadeia produtiva.

Entre as diretrizes que garantiram uma maior normalidade e determinação de padrões adequados à legislação dessas atividades econômicas, pode-se destacar a criação da Lei do Vinho, em 1988, que deu clareza às diferentes classificações e normas para a elaboração de produtos vitivinícolas no país; e o Regulamento Vitivinícola do Mercosul, de 2004, que determina imposições de regras para a comercialização dos produtos dentro do bloco econômico regional.

Mais recentemente destaca-se, também, a regularização normativa de produtos que ainda não estavam regularizados (ainda não possuíam ordenamento jurídico), apesar de já serem produzidos no país. Dentre esses produtos, destacam-se as sangrias, os coquetéis, além de bebidas e néctares de uva.

Mesmo que se considere importante a normalização para os novos produtos, o presente trabalho realça a dúvida gerada pela regularização de um produto que tem dificuldades para posterior fiscalização de sua composição, como os néctares e as bebidas de uva, devido à falta de uma metodologia que avalie suas composições. Assim, não existem garantias nenhumas quanto ao que realmente está sendo tomado, apenas ficandose com a esperança de que a empresa que elaborou o referido produto seja honesta.

\section{Considerações Finais}

A análise dos diferentes cenários e desafios enfrentados pela cadeia produtiva vitivinícola gaúcha, no que se refere às restrições e possibilidades derivadas da atual configuração de seu ambiente institucional, mostra que esse ambiente atua duplamente, ou seja, tanto pode ser um ente facilitador de novos processos que visem uma melhor inserção produtiva e tecnológica nos mercados interno e externo, como também pode atuar 
em sentido contrário a essa meta. Assim, percebe-se que o ambiente institucional da cadeia é um fator que possibilita maior possibilidade de desenvolvimento, ao mesmo tempo em que opera como agente restritivo do próprio desenvolvimento que está sendo buscado. Trata-se, portanto, de um papel duplo no que se refere à competitividade.

Em relação às políticas governamentais vigentes no Brasil e no RS, verificou-se que estas exercem grande influência no desenvolvimento das atividades da cadeia vitivinícola, principalmente em relação às políticas de comércio exterior, tributária, de financiamentos e fiscalizatória.

A atual inserção externa brasileira no mercado mundial é uma das políticas que afetaram e ainda afetam enormemente as atividades da cadeia, tanto acirrando a concorrência no mercado nacional de vinhos finos e espumantes, como também pela necessidade da cadeia de se adaptar aos novos tempos, buscando avanços nas relações entre os segmentos, nas estratégias adotadas para se inserirem no mercado, na utilização de processos produtivos mais modernos tecnologicamente, entre outros. Assim, essa nova ordem econômica exerce um duplo efeito sobre a cadeia: tanto pode apresentar-se como um fator de risco para sua sobrevivência, como também pode se constituir em um veículo de propagação cada vez maior da necessidade de evolução técnica, organizacional e empresarialmercadológica.

Cabe aqui destacar que esse aprimoramento mercadológico, tecnológico, de govenança e nas estratégias empresariais é bem superior nos segmentos ligados à produção de vinhos finos e espumantes (esses enfrentam forte concorrência externa), comparativamente à produção de vinhos comuns e outros derivados, cuja concorrência está fortemente atrelada às condições do mercado interno, onde a liderança do RS é inconteste.

Em contrapartida, a política tributária afeta negativamente a cadeia vitivinícola gaúcha, visto que a tributação é elevada comparativamente aos principais concorrentes externos, tanto para a compra de insumos importados como para a produção e venda de vinhos e espumantes. É também essa elevada tributação que cria enormes incentivos para a venda de vinho comum a granel para outros estados, ao invés de ser engarrafado na origem. Esse procedimento se beneficia, ainda, das eficientes estruturas de engarrafamento e distribuição localizadas nos estados do centro dinâmico do país.

No que se refere à política de financiamentos, verificou-se a presença de diversos instrumentos para a viabilização das atividades de custeio e investimento dos viticultores e da agroindústria, além da possibilidade de os primeiros contarem com seguro agrícola. Assim, destacam-se principalmente o PRONAF e os programas do BNDES, além de outros menos utilizados. Quanto às taxas de juros cobradas na maioria desses financia- 
mentos, observou-se que poderiam ser menores, embora não possam ser consideradas aviltantes. Merece destaque também nesse item o leilão de vinhos realizados pelo Governo Federal no fim de 2006, leilão esse que serviu para a redução dos estoques de vinhos finos das cooperativas gaúchas.

A fiscalização da qualidade dos produtos nacionais e importados, por parte do MAPA e da SAA/RS, apesar de ainda não atender as necessidades crescentes da cadeia, é considerada melhor atualmente, comparativamente aos períodos anteriores. Para isso, foi decisiva a contribuição do LAREN (em 2001) e o desenvolvimento das novas metodologias que verificam a genuinidade dos vinhos, além de uma melhoria na consciência da maioria dos segmentos produtivos e organizacionais de que devem atender aos padrões legais na fabricação de seus produtos. Entretanto, no que se refere à fiscalização do comércio ilegal de produtos, destaca-se que a invasão de vinhos importados contrabandeados, sobretudo do Chile e da Argentina, aumentou muito nos últimos anos, podendo ser considerado como um fator de enorme perda competitiva dos produtos da cadeia vitivinícola do RS.

Já a legislação que regulamenta a produção e comercialização de produtos da cadeia no país é adequada, mesmo que apresente algumas deficiências. Assim sendo, diversas são as discussões nos últimos anos sobre a legislação em vigor e sua atualização, principalmente em relação aos novos produtos liberados recentemente pelo MAPA (bebidas, néctares, sangrias, etc.).

A partir dos cenários e desafios da cadeia vitivinícola gaúcha, particularmente no que se refere ao ambiente institucional, sugerem-se algumas políticas públicas e privadas que poderiam atuar no sentido de ampliar a capacidade competitiva, destacando-se:

- A equalização da carga tributária aos níveis de tributação dos principais países concorrentes do Mercosul, com redução da tributação no "custo seco" e ao longo do engarrafamento dos produtos;

- Realização da reforma tributária que priorize o fim da tributação em cascata e a desorganização tributária;

- Combate ao contrabando de vinhos proveniente, principalmente, de países do Mercosul, visando diminuir a concorrência desleal;

- Reconhecimento efetivo, por parte das administrações municipais da região da Serra Gaúcha, da importância da vitivinicultura, através da criação de novos mecanismos de apoio e suporte ao setor;

- Aumento das políticas de fiscalização da qualidade dos produtos legais de origem nacional e importada, visando coibir a adulteração dos produtos. 


\section{Referências}

BRUCH, K. L. Análise da tributação incidente na cadeia produtiva do vinho. Universidade Federal do Rio Grande do Sul (UFRGS), Centro de Estudos e Pesquisas em Agronegócios (CEPAN), Programa de Pós-Graduação em Agronegócios, Dissertação (Mestre em Agronegócios), Porto Alegre/RS, 2004.

CADASTRO VINÍCOLA DO RIO GRANDE DO SUL. Dados divulgados pela UVIBRA, 2006. . Elaborado pela Embrapa Uva e Vinho (CNPUV/EMBRAPA), Coordenação de Loiva Maria Ribeiro de Mello, CD-ROM, 2005.

CÁRIO, S. A. F.; PEREIRA, L. B.; SOUZA, J. P. Características do padrão produtivo e determinantes da competitividade: requerimentos para a construção de vantagens competitivas. In: PEREIRA, L. B.; CÁRIO, S. A. F.; KOEHLER, M. Padrão produtivo e dinâmica econômica competitiva: estudo sobre setores selecionados em Santa Catarina. Florianópolis/ SC, Imprensa Universitária da UFSC, PPGE/UFSC, 2001.

COUTINHO, L. A terceira revolução industrial e tecnológica: as grandes tendências de mudanças. Revista Economia e Sociedade / Instituto de Economia da Unicamp, n. 01, Campinas/SP, 1992.

DOLABELLA, R. V. M. A consolidação das competências organizacionais da vitivinicultura brasileira: um estudo de caso da Vinícola Miolo. Universidade do Vale do Rio dos Sinos (UNISINOS), Programa de Pós-Graduação em Administração. Dissertação (Mestrado em Administração), São Leopoldo/RS, 2006.

EMATER/RS. Associação Rio-Grandense de Empreendimentos de Assistência Técnica. Disponível em: <www.emater.tche.br>. Acesso em: jan. 2008.

FARINA, E. M. M. Q. et al. Competitividade: mercado, estado e organizações. Singular, São Paulo/SP, 1997.

FARINA, E. M. M. Q. Competitividade e coordenação dos sistemas agroindustriais: a base conceitual. In: JANK, M. S.; FARINA, E. M. M. Q.; GALAN, V. B. O agribusiness do leite no Brasil. São Paulo/SP, IPEA, USP, PENSA, FIA, 1999.

FERRAZ, J. C.; KUPFER, D. E HAGUENAUER, L. (Ed.). Made in Brazil. Rio de Janeiro, Campus, 1995.

GRASSI, R. A. Comentários sobre a aplicação empírica do conceito estrutural de competitividade. Revista Leituras de Economia Política / Instituto de Economia da Unicamp, Campinas, 1997.

HAGUENAUER, L. Competitividade: conceitos e medidas. Instituto de Economia Industrial / Universidade Federal do Rio de Janeiro, Rio de Janeiro, 1989.

IBGE. Instituto Brasileiro de Geografia e Estatística. Disponível em: <www.ibge.gov.br>. Acesso em: jan. 2008.

IBRAVIN. Instituto Brasileiro do Vinho. Disponível em: <www.ibravin.org.br > . Acesso em: jan. 2008.

KUPFER, D. Padrões de concorrência e competitividade. Texto para discussão. IE/UFRJ, n. 265, Rio de Janeiro, novembro de 1991.

LAPOLLI, J. N. et al. A competitividade da vitivinicultura brasileira: análise setorial e programa de ação com destaque para o Rio Grande do Sul. Porto Alegre/RS, Banrisul / Embrapa CNPUV / SEBRAE - RS, 1995. 
NORTH, D. Custos de Transação, instituições e desempenho econômico. Rio de Janeiro/RJ, Instituto Liberal, 1994.

RIO GRANDE DO SUL. Secretaria de Agricultura e Abastecimento (SAA/RS). Programa Estadual de Fruticultura (PROFRUTA/RS): relatório de atividades desenvolvidas 2006. SAA/ RS e EMATER/RS. Porto Alegre/RS, 2006.

SCHUMACHER, W. O vinho nacional é caro? Artigos ABE. Extraído de: <www.enologia. org.br>, 2006. Acesso em: mar. 2007.

SISTEMA ALICE. Secretaria de Comércio Exterior do Ministério do Desenvolvimento, Indústria e Comércio do Brasil (SECEX/MDIC). Disponível em: < http://aliceweb.desenvolvimento.gov.br/default.asp > . Acesso em: jan./fev. 2007.

Recebido em: 29/07/2008.

Aceito em: 29/08/2008. 